\title{
Reports
}

\section{The V-RAMP program: Building research administration and management capacity in Nigeria}

\author{
Muktar H. Aliyu' @, Zubairu Iliyasu², Donna J. Ingles ${ }^{3}$, Holly M. Cassell ${ }^{3}$, Wendy H. Lloyd ${ }^{4}$, Aima A. Ahonkhai ${ }^{5}$, Aliyu Abdu \\ ${ }^{6}$, Carolyn M. Audet ${ }^{7}$, C. William Wester ${ }^{5}$ \\ 1 Vanderbilt Institute for Global Health (VIGH), Vanderbilt University Medical Center (VUMC), Nashville, TN; Departments of Health Policy and \\ Medicine, Vanderbilt University Medical Center (VUMC), Nashville, TN, ${ }^{2}$ Department of Community Medicine, Bayero University \& Aminu Kano \\ Teaching Hospital (AKTH), Kano, Nigeria, ${ }^{3}$ Vanderbilt Institute for Global Health (VIGH), Vanderbilt University Medical Center (VUMC), Nashville, TN, 4 \\ Vanderbilt Coordinating Center, Vanderbilt University Medical Center (VUMC), Nashville, TN, 5 Vanderbilt Institute for Global Health (VIGH), Vanderbilt \\ University Medical Center (VUMC), Nashville, TN; Department of Medicine, Vanderbilt University Medical Center (VUMC), Nashville, TN; Division of \\ Infectious Diseases, Vanderbilt University Medical Center (VUMC), Nashville, TN, ${ }^{6}$ Department of Medicine, Bayero University \& Aminu Kano Teaching \\ Hospital (AKTH), Kano, Nigeria, 7 Vanderbilt Institute for Global Health (VIGH), Vanderbilt University Medical Center (VUMC), Nashville, TN; Department \\ of Health Policy, Vanderbilt University Medical Center (VUMC), Nashville, TN; MRC/Wits Rural Public Health and Health Transitions Research Unit \\ (Agincourt) School of Public Health, Faculty of Health Sciences, University of the Witwatersrand, Johannesburg, South Africa \\ Keywords: research administration, grants management, global health, capacity building \\ https://doi.org/10.29392/001c.24355
}

\section{Journal of Global Health Reports}

Vol. 5, 2021

\begin{abstract}
The increasing volume and complexity of research activities in Nigeria necessitates urgent measures to improve research infrastructure in grants administration and management. The Vanderbilt-Nigeria Research Administration and Management Training Program (V-RAMP) seeks to build infrastructure capacity in research administration and management and research ethics at a major teaching hospital in Nigeria. We will perform a mixed methods needs assessment of the administrative and management environment and develop an action plan to address infrastructure needs, prioritize processes, and guide program implementation. We will capacitate a newly established Office of Research Administration and improve the knowledge and skills of research administrators and grant managers via short term in-person trainings in Nashville, Tennessee and in Kano, Nigeria and through remote learning opportunities. We will enhance local administrative efficiency and performance of research ethics operations through training and mentoring of members and staff of the ethics review committee. Systematic processes to streamline protocols, including a Research Electronic Data Capture (REDCap) protocol tracking database and standard operating procedures in the responsible conduct of research and rigor and reproducibility will also be developed. V-RAMP will enable the creation of a high-quality research administration environment that is knowledgeable, efficient, and compliant regarding the fiscal, management and ethical standards of sponsored research.
\end{abstract}

Africa's most populous country, Nigeria, has witnessed a significant expansion in biomedical research. Scientific publications from Nigeria increased by $60 \%$ over 10 years, from 2,500 peer-reviewed articles in 2008 to more than 4,000 in 2017, constituting more than half the total number of publications from West Africa. ${ }^{1-3}$ This growth in research output, however, has not been accompanied by a proportionate increase in research administration and management capacity, an area that is critical to the development and sustainability of a successful, high-quality research environment. This deficit in research administration infrastructure is compounded by a need for robust institutional ethical oversight structures to safeguard the rights of research participants. The increasing volume and complexity of research activities in Nigeria necessitates urgent measures to improve infrastructure in grants administration (project management, financial accountability, reporting and compliance oversight), and to strengthen ethical frameworks to protect the rights and welfare of research participants.

Over the past decade, Vanderbilt University Medical Center faculty have collaborated with colleagues at the Aminu Kano Teaching Hospital (AKTH) in Kano, Nigeria to train Nigerian scientists and to launch high-impact U.S. government-funded HIV research and service programs. AKTH investigators have demonstrated the ability to meet the technical requirements associated with the successful conduct of clinical research. A recently awarded HIV and non-communicable diseases training grant is working to further capacitate AKTH investigators to become independent clinical researchers, with a specific focus on building clinical trials expertise. ${ }^{4}$ Other grants at AKTH support clinical trials in HIV-associated kidney disease, sickle cell disease and childhood epilepsy. ${ }^{5-8}$ Sustaining and scaling up this level of productivity requires complementary investments in research administration infrastructure.

This paper describes the Vanderbilt-Nigeria Research Administration and Management Training Program (V- 
RAMP), which was designed to build infrastructure capacity in research administration and management and research ethics by leveraging investments at AKTH and the commitment by AKTH leadership to address gaps in these areas. This proposed program will build on a strong, decade-long Vanderbilt-AKTH partnership and a highly successful, collaborative, and rapidly expanding portfolio of U.S. National Institutes of Health (NIH)-funded research in Nigeria.

\section{METHODS}

\section{SETTING}

AKTH is a 500-bed tertiary care facility affiliated with Bayero University and located in Kano, the most populated state in Nigeria (pop. 9.3 million). AKTH investigators have been at the forefront of major studies on HIV and other disease conditions in Nigeria. ${ }^{5-10}$

Bayero University Kano (BUK) is the academic home for clinical and basic science programs at AKTH. The BUK College of Health Sciences is composed of four faculties (Clinical Sciences, Basic Medical Sciences, Dentistry, and Allied Health Sciences). The Faculty of Clinical Sciences consists of 15 departments and 180 faculty members, > 90\% of whom have joint appointments with AKTH. The Faculty of Allied Health Sciences has five departments with a combined 80 faculty members.

Vanderbilt Institute for Global Health (VIGH) was established in 2005 to coordinate the expansion of global health research, service, and education and training initiatives and reflects Vanderbilt's commitment to forging collaborations and improving health in resource-constrained settings. ${ }^{11}$ VIGH has 15 core faculty members and 81 affiliated faculty members. VIGH engagements span the globe, including Africa, the Americas, and southeast Asia, and generate significant academic deliverables in the form of grants and peer-reviewed publications informing clinical practice and care guidelines in the critical areas of communicable (e.g., HIV/AIDS, tuberculosis, malaria, etc.) and non-communicable diseases (e.g., kidney disease/complications, epilepsy, sickle cell disease, etc.).

\section{SPECIFIC AIMS}

1. To assess the needs and gaps in research administration and management capacity and ethical review processes. A joint AKTH-Vanderbilt team will perform a mixed-methods needs assessment of the research administration and management environment at AKTH in year 1 . The process will generate an action plan that will identify and prioritize infrastructure needs and guide the implementation of Aims 2 and 3.

2. To build research administration and management capacity at AKTH by capacitating the newly established AKTH Office of Research Administration. Activities will involve short term, in-person management practicums at Vanderbilt and skills workshops at AKTH, as well as virtual training opportunities (webinars and distance mentoring).

3. To enhance administrative capacity, performance of research ethics operations and community engagement in research at AKTH. This process will involve short term, in-person workshops at AKTH, ethics fellowships at Vanderbilt, and online webinars. We will also create a Research Electronic Data Capture (REDCap) protocol tracking database, develop a toolkit of standard operating procedures in research ethics, and establish a Community Advisory Board (CAB).

\section{PROGRAM ADMINISTRATION}

V-RAMP will be led by a seven-member team of Nigerian and U.S. faculty and staff with a proven record of expertise in research governance, financial management, compliance, and contracts administration, research ethics, and program management (executive committee). These individuals were selected based on their global health expertise, experience in Nigeria, expertise in HIV research, and enthusiasm to engage and contribute to successful program implementation.

A five-member training advisory committee will advise the executive committee on training curriculum, selection of trainees, and prioritization of program activities. The training advisory committee will include the heads of AKTH and VIGH, the director of the Vanderbilt Human Research Protection Program and other respected leaders.

\section{STUDY PROCEDURES}

\section{NEEDS ASSESSMENT}

We will perform a mixed methods needs assessment of the research administration and management environment at AKTH in the first quarter of year 1 . The needs assessment will be conducted by a joint AKTH-Vanderbilt team with extensive experience conducting grants administration assessments.

The assessment will include a comprehensive REDCapbased needs assessment survey, an extensive review of the AKTH research management and ethics administration processes, as well as key informant interviews and focus group discussions with research administrators, faculty and other key stakeholders. REDCap is a Vanderbilt-developed research data collection and management platform that has been adopted by some 1,660 institutions in 94 countries. $^{12}$ The needs assessment will evaluate current AKTH pre- and post-award research administration capacity related to: research governance, reporting systems, and structure; budget management; financial systems; monitoring and reporting; compliance and audit; and other key competencies for research administration staff. Standard operating procedures (SOPs) for accounting, records management, and proposal preparation and submission will be carefully reviewed.

The needs assessment process will generate an action plan that will enable the AKTH Office of Research Administration to identify areas most in need of research administration capacity building and desired staff competencies and targets for skill development. This action plan will therefore include considerations for local situation adaptations that will inform and guide the detailed implementation of Specific Aims 2 and 3. 
Table 1. Grants management skills workshops training curriculum

\begin{tabular}{|l|l|}
\hline Pre-award & Post-award \\
\hline Funding agencies, types of grants, and components & Subcontract management; compliance, rules and regulations \\
\hline Grant writing how to's & Standard operating procedures (SOPs) \\
\hline Grant search engines & Financial tracking \& reporting \\
\hline Local research funding opportunities & Project tracking and reporting (RPPR, APR, etc) \\
\hline Human research ethics & Fiscal oversight \\
\hline eRA Commons and roles & Strategic planning and resource management \\
\hline Proposal routing forms & Program evaluation \\
\hline Effective institutional systems \& processes & Effective communication, negotiation skills and time management \\
\hline Budget \& budget justification & Effort reporting \\
\hline Project \& team design & DSMB: the basics \\
\hline The grant administrator & Leadership \& project management \\
\hline Biosketches and other support & Scientific writing \& publication \\
\hline Mock study section & Mentorship \\
\hline
\end{tabular}

APR - annual performance report; DSMB - data and safety monitoring board; RPPR - research performance progress report.

\section{SHORT TERM TRAINING FOR RESEARCH ADMINISTRATORS}

We will improve the knowledge and practical skills of AKTH research administrators via short term, in-person trainings in Nashville and Kano and through remote training opportunities. Activities will focus on strengthening the new AKTH Office of Research Administration and more fully developing the capacity of administrative and finance staff on all aspects of grant management support, including the highest quality pre- and post-award management services. Training activities will also cover coordination of institutional support for investigators as they prepare grant applications, as well as development/revision of SOPs. These short-term trainings will involve two main activities, one based in Nigeria and one based in the U.S. (Nashville):

1. SKILLS BUILDING WORKSHOPS IN NIGERIA

We will conduct grants administration short courses in Nigeria (five days in each of Years 1 and 2) to train AKTH research administrators (two cohorts, six trainees each). Course content will be informed by findings from the needs assessment (Aim 1) and a curriculum adapted from the Vanderbilt Institute for Research Development and Ethics (VIRDE), a grant writing and research ethics course for faculty from low-resource setttings and Vanderbilt Program in Research Administration Development (VPRAD), a career development program for Vanderbilt research administration staff. We will adapt VPRAD to emphasize Nigeria-relevant topics and will include topics on pre-and post-award grants management (Table 1). VUMC and AKTH faculty and staff will co-teach the course in Year 1. The Year 2 workshop will be fully transitioned to AKTH ownership. We will use experiential learning methods ${ }^{13}$ for the workshops that will include interactive lectures, videos, group work, and simulations of workplace management and leadership scenarios.

\section{GRANTS MANAGEMENT PRACTICUM AT VUMC}

Several training resources available at VUMC will help AKTH research administrators enhance their skills, observe best practices, and engage experienced mentors. We will support two staff from the AKTH Office of Research Administration during Years 1 and 2 of the grant ( $n=4$ total) to travel to Nashville to participate in an intensive four-week Grants Management Practicum that will include the following activities:

- Mentor-mentee pairing: Trainees will be paired with experienced VIGH research administration personnel to learn best practices in pre- and post-award management. Activities will build on knowledge gained during the Nigeria skills workshops. Each mentee will be assigned to shadow a mentor in their area of expertise (e.g. pre-award, compliance, finance) and will follow-up regularly over the period of the grant with a minimum of monthly video conference calls and email check-ins, and more frequently as needed (e.g., during grant submission or reporting periods, etc.).

- Responsible conduct of research (RCR) and rigor and reproducibility symposium: Trainees will attend a twoday symposium at the VU Office of Research Integrity on important RCR topics, such as conflict of interest, mentor/mentee responsibilities, collaborative research; peer review; data acquisition tools; data management, sharing and ownership; research misconduct policies; responsible authorship and publication; contemporary ethical issues in biomedical research, plans for instruction in methods for enhancing rigor and reproducibility, and the environmental and societal impacts of scientific research. The symposium will consist of lectures, breakout sessions, and facilitated case discussions. Vanderbilt staff also attend this symposium, so trainees will be able to network with Vanderbilt peers. 
- Design studios: Design studios at VUMC are roundtable discussions that bring together research experts to provide early feedback and guidance on proposals by refining research aims, promoting rigorous study designs and methods, and assuring the most effective and efficient approaches to study implementation. Practicum participants will spend two weeks with the Vanderbilt Institute for Clinical and Translational Research (VICTR) learning how to organize and conduct design studios, with the goal of implementing a similar program at AKTH. Practicum participants will have the opportunity to observe design studios firsthand and learn the operational procedures for putting a studio into practice, including procedures to request a studio, preparation of studio documents for review, and processes to prepare expert reviewers to provide quality, constructive feedback prior to grant submission.

- Process improvement: Trainees will learn efficient approaches for research administration and management through improvement of systematic processes. AKTH trainees will come prepared to share their research administration and financial management tools and policies, and we will work with them to enhance and ensure these meet USG auditing requirements, while remaining relevant to their systems. Trainees will observe and experience Vanderbilt's financial management systems, including grant submission, reporting, budget creation, general ledger reconciliation, and clinical trials management. Trainees will also be taught to use REDCap to create a single portal for grant submissions and run an operational database to track progress of ongoing studies. As the four-week Nashville training will not provide sufficient time for full REDCap training, we will enroll trainees in the popular REDCap Africa online workshop taught by our colleagues at the University of Witwatersrand, South Africa.

\section{ENHANCEMENT OF RESEARCH ETHICS OPERATIONS}

We propose training in systems strengthening and ongoing mentorship that will improve the knowledge and practical skills of AKTH ethics review board members, institutional review board (IRB) office staff and members of the Community Advisory Board (CAB) through:

1. SHORT TERM, FOCUSED IN-PERSON TRAINING AT VANDERBILT, AND AT AKTH/BUK, AND VIA ONLINE WEBINARS IN COLLABORATION WITH EXPERTS FROM OTHER REGIONAL IRBS

- Visiting fellowships: We will host two IRB staff members in Nashville in Years 1 and 2 to attend two-week visiting fellowships (total: 4 trainees). The trainees will observe four meetings of the Vanderbilt IRB and will shadow senior Vanderbilt IRB staff members. The experience will be tailored to align with AKTH IRB needs and trainee skills and interest. Each trainee will be paired with a Vanderbilt IRB staff member for ongoing mentorship and support after the completion of the fellowship program.

- Research administration ethics workshop: We will con- duct annual five-day ethics workshops at AKTH in years 2 and 3. These workshops will provide a forum for IRB and $\mathrm{CAB}$ members and AKTH faculty/staff to interact with and learn from each other. We will invite IRB staff from other Nigerian institutions as well, thereby fostering regional networking among IRBs. The Year 3 workshop will be 100\% AKTH-driven. The training will incorporate a mix of active-learning methods directed towards the enhancement of performance skills (e.g., group hands-on interactive analysis of case studies, mock protocol reviews, informed consent writing exercises, role play for obtaining informed consent) and passive learning (e.g., in-person didactics, videos, assigned readings). Case studies will be selected based on input from local collaborators and published literature, such as Family Health International's global research ethics training curriculum. ${ }^{14}$ We anticipate approximately 12 participants each year will attend the workshops (total $\mathrm{n}=$ 24).

- Research ethics webinars: We will support quarterly research ethics webinars using video conference calls throughout the program. Webinars will last $60 \mathrm{~min}-$ utes, followed by 30 minutes Q\&A/discussion. The webinars will be moderated from the U.S. and Nigeria and will be open to AKTH IRB and CAB members, IRB and Office of Research Administration staff, and AKTH faculty. Topics will be wide-ranging and incorporate analyses of locally relevant ethics cases that have generated much debate (e.g., the Trovan drug trial)..$^{15}$ We will make recordings of webinars available to regional IRBs to foster cross-institutional learning, and to further grow AKTH/BUK as a leader in research administration and ethics.

\section{PROCESS IMPROVEMENT}

We will improve systematic processes in ethical review by creating a toolkit of SOPs and a REDCap portal for tracking protocols for AKTH IRB members and staff. Trainees will be taught to use REDCap to create a single portal for initial submissions and run an operational database to track progress of ongoing approved projects. IRB staff and members will be enrolled in the Wits REDCap Africa online course described earlier under Aim 2. The tracking database will be tailored to AKTH IRB needs and shared with other Nigerian ethics committees and the National Health Research Ethics Committee (NHREC).

\section{ESTABLISH A COMMUNITY ADVISORY BOARD (CAB)}

CABs help build trust and mutual understanding of research issues and ensure that local values and cultural perspectives are respected. ${ }^{16}$ We will establish a seven-member CAB for the BUK IRB, with membership based on input from AKTH/ BUK collaborators, and focus based on results obtained from the year 1 mixed-methods need assessment. $C A B$ members will benefit from training opportunities offered in the ethics workshops and webinars, as described above. CAB members will serve as a voice for the community and study participants, and will provide advice on scientific, ethical, and operational issues regarding study design and conduct, 
Table 2. Timeline of activities by Specific Aim, with estimated trainee numbers

\begin{tabular}{|c|c|c|c|c|c|c|c|}
\hline Aims/Months & Activity (total \# of trainees) & $1-6$ & $7-12$ & $13-18$ & $19-24$ & $25-30$ & $31-36$ \\
\hline Specific aim 1 & Needs assessment & & & & & & \\
\hline \multirow[b]{2}{*}{ Specific aim 2} & Skills workshops - Nigeria (12) & & & & & & \\
\hline & $\begin{array}{l}\text { Management practicum - USA } \\
\text { (4) }\end{array}$ & & & & & & \\
\hline \multirow{6}{*}{ Specific aim 3} & Ethics fellowships - USA (4) & & & & & & \\
\hline & Ethics workshops - Nigeria (24) & & & & & & \\
\hline & Ethics webinars (40) & & & & & & \\
\hline & REDCap portal & & & & & & \\
\hline & Toolkit of SOPs for IRB & & & & & & \\
\hline & $\begin{array}{l}\text { Establish community advisory } \\
\text { board }\end{array}$ & & & & & & \\
\hline \multicolumn{8}{|l|}{ TAC meetings } \\
\hline \multicolumn{8}{|c|}{ Program evaluation } \\
\hline $\begin{array}{l}\text { Dissemination } \\
\text { activities }\end{array}$ & & & & & & & \\
\hline
\end{tabular}

IRB - Institutional Review Board; REDCap - Research Electronic Data Capture; SOP - Standard Operating Procedure; TAC - Training Advisory Committee.

recruitment, retention, and protection of participants, and dissemination of study findings.

\section{TRAINEE CRITERIA, RECRUITMENT AND SELECTION}

We will prioritize selection of staff in the AKTH Office of Research Administration and those working with the IRB. We will also target AKTH staff involved in ongoing research projects such as grant managers, project coordinators, and fiscal accounting staff, who will form a critical pool that can be used to seed the newly established Office of Research Administration. For the in-country workshops, we will collate recommendations from $\mathrm{AKTH} / \mathrm{BUK}$ management and investigators. We will also open the in-country workshops to trainees from IRBs of neighboring institutions.

Applicants for the one-month management practicum will be required to submit the following materials: 1) curriculum vitae; 2) personal statement; and a 3) letter of recommendation from supervisor and/or other professional contact (a minimum of 2 letters of recommendation required per applicant). The candidates will be interviewed by AKTH and VUMC investigators (virtually when applicable). All applications will be reviewed by the Training Advisory Committee for final selection and approval. IRB members will be selected for the Ethics Visiting Fellowships based on the recommendations of AKTH management.

Our selection process will incorporate steps to ensure all trainees who come to the US complete their training and return to Nigeria. Trainees will be required to sign a legally enforceable contract with program leadership, signifying their agreement with the clause that mandates their return to AKTH after training. We will encourage applications from qualified women and will target at least 50\% female representation across all training activities.

\section{TRANSITION OF PROGRAM IMPLEMENTATION TO AKTH}

We include a phased transition plan (Table 2). Year 1 will focus on implementing the needs assessment and developing the action plan. Year 2 will involve implementing incountry workshops and practicum experiences at Vanderbilt, while reinforcing management skills and knowledge through continued mentoring and webinars. Year 2 will also begin the transition process to AKTH, whereby the in-country workshops will be co-taught by VIGH and AKTH team members. In Year 3, AKTH faculty will take the lead in all in-country trainings (skills building and ethics workshops), and VIGH will play a supportive role.

\section{PROGRAM EVALUATION}

We will employ a multi-pronged, mixed-methods approach to continuously evaluate the program. Our evaluation logic model (Figure 1) is based on individual-, committee- and program-level measures and includes the following elements: inputs (resources), processes (program activities), outputs (products of program implementation), outcomes (changes in trainee knowledge, skills, attitudes, practices), and impact (sustainable, high quality research environment with strong ethical oversight).

We will use REDCap to track, evaluate and report training outputs, outcomes, and impact. After each training activity, individual knowledge/skills acquisition will be assessed via surveys. These surveys will include an assessment of course learning objectives, quality of instruction, areas for improvement, and unmet needs. Based on this feedback, course content and structure will be modified, if necessary. All management practicum and ethics fellowship trainees will be asked to complete individual development plans (IDPs). IDPs will include trainees' goals and career development objectives, reflections on strengths and 


\begin{tabular}{|c|c|c|c|c|}
\hline $\begin{array}{l}\text { INPUTS } \\
\rightarrow \text { Staffing, } \\
\text { Action Plan, } \\
\text { funds, } \\
\text { training, } \\
\text { institutional } \\
\text { resources, } \\
\text { faculty, } \\
\text { mentors }\end{array}$ & $\begin{array}{l}\text { PROCESSES } \\
\rightarrow \text { Complete needs } \\
\text { assessment } \\
\rightarrow \text { Recruit \& select } \\
\text { trainees } \\
\rightarrow \text { Develop training } \\
\text { curriculum \& courses } \\
\rightarrow \text { Develop indicators } \\
\text { for program } \\
\text { evaluation } \\
\rightarrow \text { Create IDPs for } \\
\text { practicum trainees }\end{array}$ & $\begin{array}{l}\text { OUTPUTS } \\
\rightarrow \rightarrow \text { \# trainees } \\
\text { completing } \\
\text { workshops, } \\
\text { practicum, and online } \\
\text { webinars } \\
\rightarrow \text { Improvement in } \\
\text { trainee knowledge } \\
\text { and practical skills } \\
\rightarrow \text { \# timely completed } \\
\text { workshops/webinars } \\
\rightarrow \text { Days between IRB } \\
\text { submission and } \\
\text { approval } \\
\rightarrow \text { \# protocols } \\
\text { reviewed per meeting }\end{array}$ & $\begin{array}{l}\text { OUTCOMES } \\
\rightarrow \text { \# courses } \\
\text { offered, \# } \\
\text { publications, } \\
\text { presentations, grant } \\
\text { proposals submitted } \\
\text { and funded, } \\
\text { citations of } \\
\text { published work } \\
\rightarrow \text { IRB tracking } \\
\text { system } \\
\rightarrow \text { Written policies } \\
\text { and SOPs for ORA } \\
\text { and IRB } \\
\rightarrow \text { Community } \\
\text { Advisory Board } \\
\text { (CAB) established }\end{array}$ & $\begin{array}{l}\text { IMPACT } \\
\rightarrow \text { Directly influence } \\
\text { national policy through } \\
\text { nationally prominent } \\
\text { leadership in research } \\
\text { administration and } \\
\text { ethics } \\
\rightarrow \text { AKTH becomes } \\
\text { center of excellence for } \\
\text { research administration } \\
\rightarrow \text { Efficient quality IRB } \\
\text { service delivery in } \\
\text { Nigeria } \\
\rightarrow \text { Infrastructure built at } \\
\text { AKTH to conduct } \\
\text { ethical, high-quality HIV } \\
\text { research }\end{array}$ \\
\hline \multicolumn{3}{|c|}{$\begin{array}{l}\text { Internal Program data: REDCap tracking database, training } \\
\text { reports, competency assessments, course evaluations, } \\
\text { process feedback, IRB records/minutes of meetings, IDPs }\end{array}$} & \multicolumn{2}{|c|}{$\begin{array}{l}\text { Post-Program assessments \& surveys: PubMed, } \\
\text { NIH RePORTER, CareerTrac, NHREC database }\end{array}$} \\
\hline
\end{tabular}

\section{Figure 1. Evaluation logic model}

AKTH - Aminu Kano Teaching Hospital; CAB - Community Advisory Board; IDPs - Individual Development Plans; IRB - Institutional Review Board; NHREC - National Health Research Ethics Committee; ORA - Office of Research Administration; SOPs - Standard Operating Procedures.

weaknesses, planned activities to attain goals, training opportunities for career development, and feedback on mentoring experience and quality of overall training.

Improvements in systematic processes will be assessed using measures of administrative efficiency, such as days from protocol submission to approval, number of protocols reviewed per meeting, proportion of protocols that are incomplete and returned to the investigator, response time to serious adverse event report, etc. We will continuously track progress made toward achieving stated goals using quantitative processes and quality measures throughout the project, e.g., number of webinars completed, number of IRB staff who attended each training, proportion of researchers satisfied with the review process, etc. Trainees will also report twice annually the number of grants applied for, received, and managed, and the amount of funding administered. All evaluation information will feed back to the TAC and Executive Committee to enhance program effectiveness.

\section{CONCLUSIONS}

V-RAMP will enable the development of resources for AKTH to expand training to all aspects of research administration and enhance the efficiency and robustness of ethical review mechanisms to help meet the growing demands of increasing research activities at AKTH. Our program offers opportunities to build trainees' skills in research administration and management through the excellent training environment at AKTH and Vanderbilt, in addition to the provision of strong academic training, seminars, workshops, and other academic activities.

A strengthened research administration structure will significantly enhance the conduct of high-impact research at AKTH. The proposed training program will assure that AKTH research staff are skilled in their administrative roles, administrative activities are efficiently performed, proposal due dates and budget targets are met, expenses are allowable, and rigorous research is ethically conducted, compliant with regulations and includes the active participation and representation of the communities involved in the study. The creation of a high-quality research administration environment at AKTH will also be of value to other institutions in Nigeria and the West African sub-region. AKTH could serve as the regional hub for research administration expertise, contributing to the sustainable growth of research administration capacity in a part of the world where such skills are in high demand, but often lacking.

\section{ACKNOWLEDGMENTS}

The authors thank Mr. Bilya Musa, Mr. Adeniyi Adeyemo, and members of the V-RAMP Training Advisory Committee.

\section{ETHICS APPROVAL}

Ethical approval was obtained from the IRBs at Vanderbilt and AKTH.

\section{FUNDING}

This work was supported by the Fogarty International Center, National Institute of Mental Health, and National Insti- 
tute of Child Health and Human Development of the U.S. National Institutes of Health, grant \# 1G11TW011819-01. The content is solely the responsibility of the authors and does not necessarily represent the official position of the National Institutes of Health.

\section{AUTHORSHIP CONTRIBUTIONS}

MA, ZI, HC, DI, WL and CWW conceived and planned the program. MA, ZI, HC and DI helped supervise the project. All authors contributed to the development of the protocol. MA, DI, CA, and CWW wrote this manuscript with input from all authors. All authors reviewed the final draft for approval.

\section{COMPETING INTERESTS}

The authors declare no conflicts of interest.

\section{CORRESPONDENCE TO:}

Muktar H. Aliyu, MD, DrPH

Vanderbilt Institute for Global Health, Vanderbilt University Medical Center,

2525 West End Avenue, Suite 725, Nashville, TN 37203, USA.
muktar.aliyu@vumc.org

Submitted: March 23, 2021 GMT, Accepted: May 08, 2021 GMT 


\section{REFERENCES}

1. Odeyemi OA, Odeyemi OA, Bamidele FA, Adebisi $O A$. Increased research productivity in Nigeria: more to be done. Future Sci OA. 2019;5(2):FSO360. doi:10.4 155/fsoa-2018-0083

2. Hassan W, Akil A, Amine T, Owango J. Scientific research in West Africa: key trends and observations. 2018;2018:1-16.

3. Confraria H, Godinho MM. The impact of African science: a bibliometric analysis. Scientometrics. 2015;102:1241-1268. doi:10.1007/s11192-014-1463-8

4. Aliyu MH, Sani MU, Ingles DJ, et al. The V-BRCH Project: building clinical trial research capacity for HIV and noncommunicable diseases in Nigeria. Health Res Policy Sys. 2021;19(1):32. doi:10.1186/s129 61-020-00656-Z

5. Galadanci NA, Umar Abdullahi S, Vance LD, et al. Feasibility trial for primary stroke prevention in children with sickle cell anemia in Nigeria (SPIN trial). Am J Hematol. 2018;93(3):E83. doi:10.1002/aj $\underline{\text { h.25012 }}$

6. Abdullahi SU, Wudil BJ, Bello-Manga H, et al. Primary prevention of stroke in children with sickle cell anemia in sub-Saharan Africa: rationale and design of phase III randomized clinical trial. Pediatr Hematol Oncol. 2021;38(1):49-64. doi:10.1080/088800 $\underline{18.2020 .1810183}$

7. Aliyu MH, Abdullahi AT, Iliyasu Z, et al. Bridging the childhood epilepsy treatment gap in northern Nigeria (BRIDGE): Rationale and design of preclinical trial studies. Contemp Clin Trials Commun. 2019;15:100362. doi:10.1016/j.conctc.2019.100362

8. Aliyu MH, Wudil UJ, Ingles DJ, et al. Optimal management of HIV- positive adults at risk for kidney disease in Nigeria (Renal Risk Reduction "R3" Trial): protocol and study design. Trials. 2019;20(1):341. do i:10.1186/s13063-019-3436-y
9. Sani MU, Cotter G, Davison BA, et al. Symptoms and Signs of Heart Failure at Admission and Discharge and Outcomes in the Sub-Saharan Acute Heart Failure (THESUS-HF) Registry. J Card Fail. 2017;23(10):739-742. doi:10.1016/j.cardfail.2016.09.0 $\underline{16}$

10. Iliyasu Z, Kassim RB, Iliyasu BZ, et al. Acceptability and correlates of HIV self-testing among university students in northern Nigeria. Int $J$ STD AIDS. 2020;31(9):820-831. doi:10.1177/09564624 20920136

11. Vermund SH, Sahasrabuddhe VV, Khedkar S, Jia Y, Etherington C, Vergara A. Building global health through a center-without-walls: The Vanderbilt Institute for Global Health. Acad Med. 2008;83(2):154-164. doi:10.1097/acm.0b013e318160b $\underline{76 \mathrm{c}}$

12. Harris PA, Taylor R, Thielke R, Payne J, Gonzalez $\mathrm{N}$, Conde JG. Research electronic data capture (REDCap)-a metadata-driven methodology and workflow process for providing translational research informatics support. J Biomed Inform. 2009;42(2):377-381. doi:10.1016/j.jbi.2008.08.010

13. Kolb D. Experiential Learning. Prentice Hall; 1984.

14. Rivera R, Borasky D. Fhi360 Research Ethics Training Curriculum. 2nd ed.; 2020. Accessed May 6, 2020. https://www.fhi360.org/sites/all/libraries/webp ages/fhi-retc2/RETCTraditional/intro.html

15. Ezeome ER, Simon C. Ethical problems in conducting research in acute epidemics: the Pfizer meningitis study in Nigeria as an illustration. Dev World Bioeth. 2010;10(1):1-10. doi:10.1111/j.1471-884 7.2008.00239.x

16. Matthews AK, Anderson EE, Willis M, Castillo A, Choure W. A Community Engagement Advisory Board as a strategy to improve research engagement and build institutional capacity for community-engaged research. J Clin Transl Sci. 2018;2(2):66-72. doi:10.101 $\underline{7 / \text { cts. } 2018.14}$ 